\title{
Pedagogies of Inclusion: A Critical Exploration of Small-Group Teaching Practice in Higher Education
}

Gibbs, Jacqueline (a), J. Hartviksen (b), A. Lehtonen (c) and E. Spruce (d)

Author Affiliations: (a) Department of Criminology and Sociology, Middlesex University

London, London, UK; (b) School of Humanities, University of Brighton, Brighton, UK; (c)

Department of Sociology, University of Northampton, Northampton, UK; (d) Department of Gender Studies, London School of Economics and Political Science (LSE), London, UK 


\title{
Pedagogies of Inclusion: A Critical Exploration of Small-Group Teaching Practice in Higher Education
}

\begin{abstract}
This paper provides a critical examination of inclusion as a pedagogic principle through a practicebased interrogation of contemporary 'good practice' strategies for encouraging inclusion in smallgroup teaching. The analysis emerges from our experiences of delivering four classroom exercises that are frequently proposed as strategies for increasing inclusion, and borrows insight from critical intersectional feminist pedagogy to interrogate normative discourses of inclusion in HE. We argue that both the terms of inclusion, and the assumption that (verbal) participation is itself a straightforward sign of improving inclusion in classroom spaces, require interrogation. This article thus responds to the proliferation of inclusion discourses in contemporary UK HE, by identifying some of the potential pitfalls of viewing inclusion through the limited lens of participation.
\end{abstract}

Keywords: feminist pedagogy, inclusion, participation, small-group teaching 


\section{Introduction}

In recent years, 'inclusion' has emerged as a normative pedagogic principle in UK Higher Education (HE). ${ }^{1}$ Particularly in the critical social sciences, where questions of social justice structure the field, the quest for more inclusive education is widely considered a self-evident good. Along with initiatives to 'transnationalise' or decolonise the curriculum, and ongoing efforts to widen participation at 'elite' universities, the educational 'grey literatures'2 reflect a belief that teaching practices can themselves be instrumental in fostering more inclusive universities. It is this way of thinking through inclusion - as a political commitment that can be 'practiced' by teachers in the seminar-space - that is the focus of our research.

In this article, we build on our experience of team-teaching a 15-week masters-level gender theory module at the London School of Economics (LSE) to offer a practice-based interrogation into the normative value of inclusion. ${ }^{3}$ Through participant observation and teacher reflections, we consider four classroom activities that form part of our 'teaching toolbox' (exercises we routinely incorporate in our teaching practice), and that are also frequently associated with improved classroom inclusion. Whilst we found that each of these activities presented a distinctive opportunity to disrupt the status quo of the seminar-space in ways that reflect our political investments in intersectional feminist pedagogy (Ellsworth 1989; hooks 1994), the extent to which the exercises were necessarily and universally inclusive is less clear.

Along with evaluating the ways in which these particular activities foster inclusion, this article also contributes to conceptual clarification of 'inclusion' itself. Despite the frequency of references to inclusion within UK HE, and the proliferation of practice-based guidance on inclusive teaching, surprisingly little attention has been afforded to what inclusion actually looks like in the small-group teaching setting and, relatedly, how we might go about fostering inclusion. One impact of this lack of conceptual clarity is that inclusion risks being emptied of meaning, emerging as a buzzword that - as has been critiqued of the associated emphasis on 'diversity' in

\footnotetext{
${ }^{1}$ Although carried out in the specific context of UK Higher Education, the increasing transnationalisation of HE notably in terms of student profiles, educational ideologies, and pedagogic materials - means that our research has relevance to HE contexts beyond the UK.

2 'Grey literature' refers to non-commercial or unpublished material - for HE pedagogies this is predominantly in the form of blogs, VLOGS, online resource-sheets, and university guidance documents.

${ }^{3}$ This module is taught through weekly lectures, delivered by permanent members of faculty, and seminars, typically delivered by Graduate Teaching Assistants and Fellows. Seminars have approximately 15 students and are designed to be highly interactive: it is this emphasis on student-led learning that leads us to use the term 'seminar-space' rather than classroom, although there are clear overlaps between the two.
} 
HE discourses (Ahmed 2012) - paradoxically 'stands in place' of transformative approaches to inclusion. The lack of conceptual clarity, moreover, risks entrenching a slippage that is noticeable in the grey literature: between inclusion as a teaching objective, and participation as the transparent sign of inclusion. Moreover, as Mariskind points out, "what "participation" refers to is often taken for granted and rarely critiqued' $(2013,596)$. These slippages are likely, we suggest, to produce particular contradictions amongst some neurodiverse and disabled students, students for whom English is not a first-language, and those who are less familiar with the Socratic Method. ${ }^{4}$ To counter the risk of further excluding students for whom inclusion and participation are not codependent, this article also aims to problematise the circulation of inclusion as participation.

To meet our dual objectives of conceptual clarification and experience-based interrogation, we first proceed with a review of both literatures on 'good practice' approaches to inclusion in the HE seminar-space and intersectional feminist pedagogy. We then provide an in-depth account of our experiences in the seminar-space, evaluating the ways in which our four teaching practices were able to contribute towards inclusion. Finally, we conclude with a discussion of the need to complicate understandings of inclusion in HE, suggesting that intersectional feminist pedagogy points to a more constrained, yet also more transformative, approach to inclusion.

\section{Literature Review}

\section{Good Practice Approaches to Inclusion}

With the recent prominence of universal design for learning (UDL), as well as a broader recognition of the varied needs of students accessing $\mathrm{HE}$, inclusion has become a normative pedagogical principle. Inclusion discourses are often coupled with institutional policies for 'widening participation' in response to persistent attainment gaps and retention and hiring inequalities across universities. ${ }^{5}$ Across the academic and grey literatures on 'good practice' for fostering inclusion in the HE seminar-space, several approaches recur. Amongst these, group

\footnotetext{
${ }^{4}$ These latter two groups of students are particularly visible at LSE, where over 100 languages are spoken on campus' and more than $50 \%$ of students come from 'Overseas', as detailed on the LSE website.

${ }^{5}$ See for instance the UK Government's 'Agenda for Widening Participation in Higher Education' (Connell-Smith and Hubble 2018); the European Council's Recommendation on 'Common values, Inclusive Education, and the European Dimension of Teaching' (Council of the European Union 2018); and the AdvanceHE (formerly the Equality Challenge Unit) 'Equality in Higher Education: Statistical Report 2013' that 'provides national figures which can be used to consider the diversity and inclusivity of the HE student body as a whole' (Equality Challenge Unit 2013).
} 
agreements or ground rules are cited as improving student learning by generating a more respectful, and therefore more inclusive, seminar-space (Brookfield and Preskill 1999;LSA Inclusive Teaching Initiative 2017). Establishing a group agreement involves introducing - or cogenerating with students - a set of rules and conditions for a respectful and inclusive learning environment at the beginning of a module. Such agreements are understood to contribute to creating a safe learning environment by holding students and teachers accountable for their behaviour and by enhancing transparency. Further, they can help foster a sense of community and belonging 'by balancing the learning needs of the individual with the learning needs of the group' (Center for Teaching Innovation 2019).

The use of anonymity, particularly in combination with web-based learning technologies, also appears regularly as a means to enhance inclusion. In their early study of the use of anonymity in online learning, Chester and Gwynne (1998) argue that the elimination of the possibility for identification can enhance a sense of collaboration in learning. Similarly, in their study on the effectiveness of the use of pseudonyms, Miyazoe and Anderson (2011) argue that anonymity may reduce students' anxiety and promote increased engagement with classroom activities. Additionally, anonymity can promote wider participation 'by masking various social barriers such as age, gender, social status, and language proficiencies' (Ibid., 176; cf. Chester and Gwynne 1998).

Teaching activities that aim to increase or democratise student participation are also frequently cited as examples of good practice, framed as part of a broader strategy of fostering an inclusive and democratic classroom (Brookfield and Preskill 1999). For Matheson and Sutcliffe 'active student engagement' is important because it signals an expectation that 'student opinions, cultural heritage, and individual backgrounds' are valued (2016, 20). More specifically, activities that require participation from all students in a group setting tend to be seen as inherently more inclusive than activities that rely on students taking part proactively. Examples of such activities include randomly calling upon individual students (Center for Research on Learning and Teaching 2015), as well as more elaborate methods, such as circle discussions where each student speaks in turn for a specific amount of time, or exercises where everyone must participate before anyone makes a second intervention. These types of activities explicitly aim to 'even out' participation without relying on the teacher to call upon particular students, thus preempting the risk that students feel unfairly singled out, and minimising the impact of teacher bias (Ibid.). 
Overall, good practice literatures on inclusion in HE classrooms tend to favour approaches that assume a link not only between increased participation and increased inclusion, but also between increased inclusion(-as-participation) and increased learning. As Mariskind suggests, these approaches reveal a pedagogical norm 'whereby learning is demonstrated through verbal (English) fluency and activity' $(2013,601)$ - thus overlooking not just learning approaches and cultures that may not depend on verbal participation to be successful, but also other forms of participation such as active listening or reflection. The approaches briefly reviewed above - group agreements, anonymity and web-based activities, and activities that encourage or require participation from all students - exemplify this perspective, in that they all aim to foster participation, as well as, to varying degrees, a sense of identification with the seminar-space.

\section{Complicating Hegemonic Understandings of Inclusion: Intersectional Feminist Pedagogy}

Our interest in contemporary inclusion discourses developed from the interdisciplinary gender studies environment in which we teach, where questions of power dynamics, participation, and collaborative knowledge-building are considered crucial and ongoing (hooks 1994; Parry 1996; Romney et al. 1992). Whilst we believe that feminist pedagogy provides us with ways of working through the ambivalence of mainstreaming inclusion in $\mathrm{HE}$, we are also conscious of the amenability of some critical pedagogies to contemporary neoliberal accounts of inclusion (Gibson 2015). Sharing a broader critique of the increasing marketisation of HE institutions (Brown 2015), we consider inclusion discourses as potentially embroiled in institutional 'performance culture', where the auditing and measuring of inclusion can obscure, as much as foster, its realisation (Ahmed 2012; Gibson 2015).

Critiques of generalised renderings of inclusion have been developed within feminist of colour and decolonial pedagogical approaches, which have questioned the 'flattening' of structural and intersecting inequalities within generic, privatised notions of inclusion and diversity (Mohanty 2013, 973; cf. Gibson 2015). From these perspectives, a failure to examine the multidirectional, interpersonal, and structural experiences of power that are felt (and formed within) institutional settings occurs alongside the absorption of these critiques into a language of inclusion or diversity in HE (Ali 2009; Gibson 2015; Mirza and Gunaratnam 2014). As Ahmed (2007) writes in her exploration of 'diversity work' in HE, diversity (like inclusion) often acts as an institutional goal that obscures the sustained racism of institutional spaces for which it is ostensibly engaged as a 
repair. Similarly, in the words of Smele et al., 'diversity management both neutralizes and seeks to profit from what are portrayed as harmless “differences" between groups of people' $(2017,690)$. These critical engagements with the ways in which universalised and individualised diversity discourses can contribute to the reproduction of sexism, classism, racism, and ableism in classroom spaces have clear parallels in the emergence of 'inclusion' as a pedagogic norm. This indicates the importance of resisting the appeal of symbolic and rhetorical evocations of inclusion in HE, and of working to complicate the 'indicators' of inclusion that frequently circulate as the rationale for pedagogical practices.

Specifically, this paper builds on these perspectives to question the contemporary tendency to view inclusion through the singular lens of participation, which we argue limits our pedagogical considerations to encouraging students to speak. Mayuzumi et al. (2007) explore questions of participation in their interviews with female Japanese students in the Canadian postgraduate setting, and argue that 'dynamic' accounts of diversity would attend to the classroom as a relational experience between self and other, in which expressions of participation are read through gendered and racialised frames. Their discussion raises the important distinction between speaking and being heard, and the frames of 'otherness' through which participation is received and silenced. As Ellsworth writes in her exploration of anti-racism and teaching 'critical pedagogy', the expectation that elevating 'student voice' contributes to an inclusive space ignores how the voices of marginalised students, often already abstracted from norms of participation, are 'constructed in opposition to the teacher/institution when they try to change the power imbalances they inhabit in their daily lives, including their lives in schools' $(1989,310)$.

Following the attention that Ahmed (2007), Ali (2009) and Puwar (2004) have drawn to the experiences of women of colour within institutional spaces with entrenched racialised and gendered normativities, we question the assumption that verbal presence can be taken as a sign of meaningfully improved inclusivity. When we consider both the multiplicity of exclusions likely taking place in the seminar-space, and that claims to democratised participation might themselves produce forms of exclusion, it is clear that participation alone cannot act as the sign of inclusion. Silent listening, resistance towards class discussions, and refusals to engage with gendered, racialised, and classed expectations within the seminar-space also appear as actions that might radically challenge understandings of participation as they are currently framed in good practice models (Harlap 2014; Mariskind 2013). 
Moreover, these intersubjective and emotional dimensions of the seminar-space - which can be both momentary and build over time - put into question the certainty with which facilitators and students can know, rationally enact, and measure the universal inclusivity of classroom exercises. For example, Karlsson (2015) argues that some students' expressed feelings of comfort with 'free-flowing' verbal exercises in the classroom relies on an existing familiarity with particular academic codes. That is, such feelings of comfort speak to broader structural experiences even as they emerge as individual preferences in the seminar-space. This suggests that a relational, temporal, and multi-directional understanding of classroom dynamics is essential; in other words, what may perform an inclusive learning function in one class, may contribute to an exclusionary dynamic in another. Without attention to such relational dynamics of power, signs of inclusion act as 'problematic aspirations' (Burke 2015,397). Not only will universal frameworks for inclusion struggle to address students' different, and simultaneously occurring, forms of exclusion within learning spaces, but universalised signs of inclusion - such as participation - might also perpetuate these exclusionary dynamics.

\section{Methodology}

Our research comprised participant observations and teacher-researcher reflections recorded throughout the duration of a 15 -week interdisciplinary core module. ${ }^{6}$ The module introduces students from a range of academic backgrounds to key theories in gender studies. It is delivered on a weekly basis through a 90-minute lecture (approximately 90 students) and a 90-minute seminar (approximately 15 students). Along with several other colleagues, the authors worked as seminar teachers for the duration of the module.

This research emerged from a conversation in a training session prior to the module, where we identified a joint commitment to scrutinising how our teaching practices might enhance 'inclusion'. To track and reflect on the complications that arose in turning theory into praxis, we kept research journals, adding entries after each class or relevant student encounter. On several occasions during the module, the authors met to discuss their reflections, offering an opportunity to collectively develop initial analyses and challenge each other's interpretations of experiences in

\footnotetext{
6 This project was conducted in accordance with school guidance on research ethics, prioritising student anonymity. Descriptions of the research interests and intended outputs were disseminated to students. Clear channels for reporting and feedback were established so that students could withdraw from the research at any time with no ramifications.
} 
the classroom. Undertaking the initial stages of our analysis during the module, rather than at its completion, helped deepen the ensuing reflections in our research journals and develop a more critically attuned and reflexive approach to our teaching practice. Once the module was completed, each of us identified key themes, which the discussion below emerged from. Although only able to provide a foundation, the ethnographic attitude that guided our methodological choices allowed us to respond to the tensions highlighted by (and between) an intersectional feminist pedagogical approach and good practice approaches to inclusion, drawing attention to the everyday operation of 'inclusion discourse' and the variability of its implications in our particular HE context. ${ }^{7}$

Posing problems for the idea of generalisable 'good practice' approaches to inclusion from the outset, our students have a cohort-identity that is distinctive in being highly international, multilingual, predominantly women-identified, and economically elite, whilst also including students who do not meet any of these positionings. The authors' own positionalities broadly echo this description. Almost all of the students on the module were studying MSc programmes at the LSE's Department of Gender Studies, but came from different academic and professional backgrounds. This paper collates and abstracts our observations to preserve student anonymity whilst producing insights that are useful to fellow teachers.

\section{The Praxis of Inclusive Seminar Teaching}

This section describes and critically evaluates four exercises from our 'teaching toolbox' that also appear in the good practice literature reviewed above. We examine group agreements, a collaborative Google Doc resource, a Padlet activity, and a 'circle discussion'. The first two were introduced in the first seminar as an ongoing practice, whilst the latter two constitute distinctive exercises, carried out in particular seminars. In each case we present an evaluation of both successes and risks that these practices pose for furthering inclusion in small-group teaching contexts.

\section{Group Agreements}

\footnotetext{
7 This paper centres the reflexive accounts of classroom teachers to trouble dominant discourses on inclusion. However, its insights would be productively extended, in particular, through focus groups and interviews with students.
} 
In our first lesson, we developed group agreements to address inclusion and participation dynamics in the seminar-space. This included a discussion of students being present in class discussions, whilst also acknowledging work and care responsibilities, with 'participation' defined as coming to class having completed the readings, with a willingness to bring questions into the room. The likely diversity of our students and their relationships with both each other and the readings were made explicit. The agreements highlighted issues around privilege and bias, the boundaries of 'fact' and 'objectivity', and the importance of using 'I' statements in individual contributions. Here, we emphasised the productive possibilities of discomfort in collaborative learning, drawing on the phrasing of 'generosity' to highlight some ways in which disagreement might be approached within the learning environment (Wazana Tompkins 2016). The group agreements emphasised that 'higher learning is not simply knowledge-based, but relational in focus' (Yannuzzi and Martin 2014, 709), encouraging students to invest in this relationality and the emotions it produces as 'part of pedagogical practice' (Ibid.). Our group agreements tried to foreground a feminist pedagogical approach, encouraging students to actively engage with questions of inclusion and participation in the classroom.

In practice, the success of group agreements proved difficult to measure in terms of producing - rather than just theorising - inclusion. The explicit address towards students' academic, social, and linguistic experiences might have been helpful in drawing focus towards questions of inclusion in the first seminar - and initially, one teacher suggested that some of the more fruitful conversations over the term centred questions of difference, with students expressly bringing their experience in by using 'I' statements. Certainly, we observed that some students did self-regulate their contributions in class, for example noting that they were speaking too much, or giving their turn to someone who had not yet spoken. A couple of students asked their teachers in office hours whether they were dominating seminar discussions, signaling their heightened awareness of seminar dynamics.

Two teachers, however, observed varied application of the principles of speaking and space-sharing outlined in the agreements, dependent on the activity. Within smaller group discussions, students made efforts to share, explain, and take time in expressing their thinking, with some students asking for contributions from quieter students. This was rarely the case in plenary discussions, however, where the same few students tended to lead the discussion each week. 
While our hope was that the group agreements would visibilise some of the assumptions embedded in discussions of gender, race, sexuality, nationality, and faith in the seminar-space, it is difficult to speak to the students' ability to enact an inclusive learning environment, as opposed to encouraging students to critically reflect on its possibility, benefits, and limitations (Barnett 2011). Increased self-reflexivity in students did not necessarily lead to self-policing in actual classroom situations. Indeed, where group agreements prioritise the creation of a safe learning environment 'where all know that their ideas and viewpoints will be respected' (Center for Teaching Innovation 2019, emphasis added), the emphasis on the validity of everyone's contributions may, in fact, serve to reinforce existing power imbalances (Ellsworth 1989; Mariskind 2013).

Significantly, some of us felt that introducing the agreements at the very beginning of the module potentially fostered a feeling of completeness, a sense that inclusion and participation dynamics have been dealt with. One teacher noted that attempts to engage with questions of intersectional inclusion generated observable disengagement, specifically from students who were familiar with group agreements due to prior engagements with activist spaces. We interpret this apparent disinterest to suggest that the repetition or mainstreaming of group agreements might actually undermine the reflexivity they are intended to foster. Thus, thinking of new ways to generate such discussions in earlier classes may lead to genuine engagement with questions of inclusion - preventing group agreements from becoming a 'tick box exercise' (Ahmed 2012). Indeed, when classroom dynamics continue to be problematic despite the group agreement, it becomes challenging for teachers to address these dynamics explicitly, partly because the agreement should have already dealt with the issue.

Finally, as discussed above, the affective dimensions of the group agreement are difficult to anticipate or capture. We were left wondering about the assumption implicit in group agreements that students are self-reflexive to the extent that they are able to moderate their behavior and feelings in response to a set of predefined rules. As Boler argues, 'the analysis of utterance in the classroom requires more than rational dialogue' $(2004,8)$, suggesting that emotions are deeply involved in constructing our viewpoints and our responses within seminar interactions. Teachers using group agreements may, then, overestimate students' capacity for reflexive decision-making, and not take into account the role of emotions in the formation of opinions, prejudices, or behaviours (Barnett 2011; Smele et al. 2017). While group agreements do 
provide a useful tool for setting and managing student expectations, they do not, and cannot, address all problematic or disruptive behaviours, nor can they alone correct power differentials or structural inequalities in the seminar-space.

Overall, group agreements appear both to meet 'good practice' for teachers attempting to address questions of inclusion and participation, and to complicate understandings of inclusion from a feminist pedagogical perspective. They provided a useful blueprint for an inclusive seminar-space, particularly in terms of coaxing students to critically engage with classroom power dynamics. At the same time, precisely because they act as a blueprint for an inclusive classroom - rather than a tool through which to enact it - it is possible that group agreements are limited in the extent to which they can conceptually complicate inclusion, suggesting that such complex questions are resolved prior to, rather than generated within, learning environments. Finally, group agreements may underestimate the role of the non-rational in directing behaviour, and correspondingly overestimate students' capacity to modify their behaviour according to a set of predefined principles.

\section{Google Doc Collaborative Resource}

Teachers aimed to foster inclusion beyond the seminar-space through a collaborative Google Doc that was established as an accessible, flexible, and anonymous space for students to share resources and reflections. Each week, several students were asked to post a question, article, video, or brief reflection related to that week's course material. This, we hoped, would complement material covered in the seminars. At the beginning of each class, or during different activities, students were asked to reflect on the submissions. Importantly, this activity was not assessed, but required independent work from students. Logistically, class teachers managed the resource differently, but all students were expected to devote roughly 30 minutes at different times throughout the term to contributing to the resource. Responding to key UDL principles of providing opportunities for perception, expression, and comprehension (Rose and Meyer 2006), this activity offered an online space for students to approach course material in an informal manner, and to learn from their peers in an anonymised space.

One teacher received positive feedback regarding the collaborative resource from several international students, because it allowed students to share and relate to material beyond the scope of the class. Students related class material to different transnational - particularly their home - 
contexts, speaking to principles outlined in the group agreements. One teacher also found that students commented less than in other years on the 'irrelevance' of particular topics, perhaps suggesting that the resource allowed students to relate material to their specific disciplinary interests.

The independence and personal initiative the activity demanded, however, were also a detriment to its success overall. At times, participation was limited, and we found that students seemed to collectively abandon the document as the semester progressed - despite many suggesting they found it a useful addition to their learning. It is possible that the anonymous and non-assessed aspects of the resource meant that students did not feel pressure to keep up with it (or felt pressure not to, when others were not contributing). In this sense, the benefits of the document being an anonymous and spaced-out form of participation also negatively impacted students' commitment to it.

Furthermore, on occasion material was posted that - without adequate explanation presented uncritical, or problematic views. Without the ability to engage these contributions in dialogue at the moment of their articulation, on these occasions the resource became an ambivalent pedagogical site. At least one teacher, therefore, also felt compelled to 'call out' some contributions in ways that may have undermined the intention of the resource to open up space for independent student contribution. This teacher felt that students were not always prepared to approach the materials critically, and expressed concern that it risked entrenching a sense of exclusion by mirroring existing power dynamics. Relatedly, another teacher found that students tended to focus on one or two key posts when discussing the week's resources, rather than all submitted material. This meant that equal time was not always allocated to each post - potentially fostering a feeling that not all thoughts or perspectives were equally attended to.

Ultimately, then, while the collaborative resource offered opportunities for promoting inclusion beyond oral participation and for diversifying contextually or linguistically limited curricula, its success was limited by its reliance on independent student work, as well as by its positioning within dynamics of linguistic, contextual, and representational privilege within the seminar-space. While it gave students a space through which they could engage with course material in a flexible manner, it also relied on students being respectful in their engagements. Because the space was anonymised, the resource also resulted in some instances of disrespectful behavior, or compounded classroom power dynamics - paralleling the findings of Beaudoin 
(2002), Chester and Gwynne (1998), and Dreyfus (2002), and illustrating the advantages and contradictions of using anonymity to enhance inclusion.

\section{Padlet}

Eleven weeks into the module, we introduced an exercise using Padlet, a web application that allows users to post to a digital canvas. With some important differences, elaborated below, our use of Padlet mimicked that of a conventional pin-board and notelets. Students were given the link to a virtual canvas, with a few sentences of guidance that reiterated the teachers' verbal instructions. For the first 15 minutes of the seminar, students were encouraged to use mobile devices to make contributions, comment on each other's material, and give star-ratings to contributions they found helpful. We chose the 'canvas' format for displaying contributions, allowing content to be grouped, layered, and organised by students, rather than tiled sequentially according to time of upload. The Padlet was password protected, and students contributed anonymously. ${ }^{8}$

The objective of the exercise was to draw on readings, lecture material, Google Doc material (discussed above), and individual reflections to collaboratively produce a pin-board full of quotations, questions, and interactions. This exercise would, we hoped, provide a space for peerlearning; serve as the first stage of preparation for a debate, which would follow as the main seminar exercise; and finally, generate a resource for ongoing reflection and revision. In contrast to conventional knowledge-mapping exercises, where the teacher usually takes back ownership as they add contributions to a white-board or sum up plenary discussions, this format allowed students to 'maintain ownership of ideas throughout the process' (Laurillard 2009, 7), thus according with feminist pedagogical principles that seek to de-centre power relations (Ellsworth 1989).

The format of the Padlet allowed students to work at their own speed and level of involvement, and several teachers reported increased levels of energy amongst the students. This presented a different way of negotiating the familiar dynamic of having to suppress some - more vocal - student contributions in order to make space for more reticent students. Indeed, three of us observed that it was the more reticent students who seemed the most focused on the document. Students were able to make use of dictionaries and translation technology, and even perform quick online searches without feeling like they were 'holding up' faster students. During the activity,

${ }^{8}$ At the time of research, Padlet was an open access platform 
students could read large volumes of information, gaining corroboration and/or corrections to their contributions. These features also seemed to encourage participation in subsequent exercises: in later small-group discussions, one teacher noticed some of the more reticent students use the Padlet as a way of introducing their ideas. Another teacher noted that a student who had never previously voluntarily participated in class discussions made several contributions in the later 'high stakes' context of a debate. In another seminar, however, students barely mentioned the Padlet in the following activity, raising doubt about the usefulness of the exercise and the transferability of the knowledge assembled through the activity.

Despite the benefits, there were also several posts that deployed 'the technology as a personal stage for silliness' (Fuchs 2014, 8), using patronising or humorous contributions to potentially undermine the activity. More worryingly, one seminar leader was concerned that the exercise opened the ground for peer 'trolling.' From this perspective, rather than the anonymity of the platform fostering a sense of inclusion, it appeared to decrease the sense of accountability and respect that we demanded in face-to-face discussions, paralleling the limitations observed in the use of the Google Doc collaborative resource - with potential implications for distance-learning environments. Indeed, some research has suggested that anonymity in online spaces can facilitate 'disinhibited' behaviour, potentially diminishing the effectiveness of anonymity in creating an inclusive learning environment (Beaudoin 2002; Dreyfus 2002). Chester and Gwynne suggest, similarly, that 'without the usual non-verbal cues and well established etiquette that exist in faceto-face exchanges, users are less likely to feel constrained by convention' (1998, np).

Further, several students voiced active resistance to the activity either out loud, by laughing, or through non-verbal cues such as eye-rolling or pushing their laptops away. In this case, more confident students - whose contributions typically set the tone in seminar discussions - found a new way to inhabit a dominant role. Relatedly, teachers also observed a feeling of frustration from more confident students, particularly over the notelets 'jumping around' and posts being responded to before they had a chance to contribute.

With more time, the Padlet exercise could have proven a useful prompt for students to reflect on the experience of a learning activity that is not the best 'fit' to their personal approach to learning, thus helping foster empathy towards learners who experience frustration with other, more commonly used, learning formats. Our experience however, illustrates the extent to which students were accustomed to more conventional methods of in-class participation, and that 
incorporating intersectional feminist pedagogy into our teaching also relies on students' investment in questioning these norms - to not just 'proceed as usual' (Karlsson 2015, 662). Aligning with our sense that good practice approaches may not account for multiple forms of classroom exclusion, the Padlet may have addressed questions of verbal inclusion and pace, while simultaneously exacerbating the space for peer 'trolling' and non-generosity. As such, the Padlet allowed for further reflection on what seems to us an important distinction between increasing and democratising participation (whether non-verbal or written), and facilitating environments that cater to questions of inclusion in relation to power hierarchies.

\section{Circle Discussion}

While our 'teaching toolboxes' include various activities that encourage participation from all students, in week eight of the module we used a 'circle discussion' - a variation of Brookfield and Preskill's (1999) 'circle of voices' - as an activity for the entire seminar. Circle discussions involve everyone in the group taking turns to speak in response to set questions, others' contributions, and/or course materials. Importantly, students can only speak when it is their turn, but can respond to multiple points when speaking, and are encouraged to take notes throughout the rounds. Sometimes a time limit is set for individual student contributions - Brookfield and Preskill (Ibid.) recommend three minutes. In our version of the circle discussion the teacher was part of the circle, and only participated in the discussion when it was their turn. We started the circle discussion by posing two broad questions and giving students a couple of minutes to reflect, but also gave students the option of responding to the lecture, readings, other students' contributions, and/or other materials. The teacher also provided additional questions at each turn. The circle discussion lasted 50-65 minutes, allowing two or three rounds to be completed during the seminar.

The circle discussion is explicitly intended to democratise participation, give students the chance to practice active listening, and promote continuity (Ibid.). We wanted to use the circle discussion specifically to address the (related) issues of uneven participation, inactive listening, and lower participation rates of non-native English speakers in our seminars. Some students whose first language is not English, and who, additionally, had no prior experience of HE in the UK or in English, had expressed to us in office hours that participation in seminar discussions was difficult

for them specifically because of the pace of the discussion. These students often felt the conversation had moved on by the time they had formulated a response. The circle discussion 
specifically intervenes in this dynamic by removing 'the stress of having to decide whether or not to try to jump in after another student has finished speaking' (Ibid., 63; cf. Mariskind 2013).

Many students responded positively to the exercise, noting that the discussion format allowed for increased student contributions, as well as a more multi-faceted conversation. In one teacher's case, this seminar had by far the most equal levels of student participation, with students who struggled to intervene in open plenary discussions participating much more than usual. In addition to an equalising effect, the circle discussion allowed for multiple conversations to take place simultaneously. Students took to the format well, and frequently began their contributions with statements such as 'I want to respond to what X said...' and 'What you said was interesting and made me think of....'. Some students used their turn to draw connections to previous topics and other modules, as well as to bring in examples from the media, arts, and policy fields. Additionally, some students' contributions performed the function that the teacher would have usually taken on, for example making connections between another student's contribution and the readings, the lecture, or a topic covered earlier in the module.

However, some students also expressed that while the 'intention' of the circle discussion was well-meaning, the structure was paternalistic, or unfairly stifled more talkative student contributions, suggesting that the activity did not necessarily lead to reflection on class dynamics, or on how preferences for participation reflect issues of power within the classroom (Karlsson 2015). Moreover, although the dynamic in the seminars in which we used the circle discussion was more even than usual, this effect did not carry on to following seminars. In fact, in the next class the participation dynamics seemed exaggerated in their unevenness: some students dominating discussions and lack of participation from others persisted. As with the group agreement, the circle discussion invited explicit reflection from students on questions of power and inclusion/exclusion dynamics in the seminar-space, alongside strategically addressing uneven participation. Yet, similarly to the group agreement, the circle discussion seemed to promote such reflections as contained to the specific activity or class - rather than encouraging broader student reflection and practical action in subsequent classes.

The narrow definition of participation itself - as speaking - in the context of the activity may have also resulted in non-verbal modes of participation, such as listening, note-taking, and responding non-verbally being overlooked (Mariskind 2013). Moreover, the activity highlighted that the democratisation of contributions to classroom discussions does not necessarily lead to the 
democratisation of whose contributions are heard (Mayuzumi et al. 2007), and consequently, left us wondering whether some students' choice to participate more may have, in fact, increased their sense of alienation, due to not feeling heard.

Finally, equalising participation-as-speaking may benefit some students more than others, depending on the kind of difference they embody and bring into the seminar-space. Harlap argues that 'participants from marginalized groups may choose silence as a strategy to resist voyeurism, the dominant group's desire to have access to all knowledge, including the experiences of the oppressed' (2014, 224-5; cf. Smele et al. 2017). Differences that arise from and manifest deepseated structural inequalities, such as race, gender, and class differences, may not be as easily 'corrected' with active participation(-as-speaking). Overall, and similarly to the other practices discussed above, our experience with the circle discussion serves to highlight many issues arising from inclusion being defined narrowly - as participation.

\section{Conclusion}

In reflecting on our own experience of these 'good practice' approaches to fostering inclusion in the seminar-space, some unanticipated concerns emerged. Activities that responded practically to questions of participation, such as the circle discussion; or created space for differing forms of participation, such as the Google Doc and Padlet; did not necessarily encourage students to engage in the broader, critical reflection on inclusion that we had hoped. Indeed, these approaches may have even exacerbated problematic dynamics both inside and outside of the seminar-space. Despite these reservations, they appeared successful in giving us the tools to facilitate broader spoken or written participation, and in providing an opportunity to signal our openness to being held accountable for our role as seminar teachers - something we consider central to an intersectional feminist pedagogical approach to inclusive teaching. This was reflected in student evaluations of the seminars, where our investment in fostering an inclusive teaching environment was favourably remarked upon.

The group agreements, as well as the invited student reflection on the dynamics of the circle discussion, drew more directly on an intersectional feminist pedagogy that incorporates a reflexive critique of power. Yet, these facilitations did not necessarily allow us to enact such criticality or reflexivity in the seminar-space, and may have even suggested that such dynamics could be 'resolved' in ways that are contradictory to our own understanding of the ongoing 
processes of exclusion/inclusion. While our explicit focus on inclusion in the seminar-space opened the door to some changes in dynamics, as well as to productive reflection from students, the exercises simultaneously confirmed that 'all speech is not free' (Boler 2004) in that speech alone cannot overcome structural inequalities in the seminar-space. In other words, the exercises and approaches discussed above functioned to highlight, rather than proactively tackle, power differences and inequalities evident in the seminar-space.

In evaluating these practices, we struggled to find signs of inclusion that function beyond the limited parameters of participation. Thus, whilst our pedagogical framework insists that we maintain a critical approach to verbal and written participation as necessarily enacting inclusion, we felt unable to adequately ascertain teaching activities that may engage, or allow room for, practices like refusal, silent listening, or reflexive critique. We felt beholden to signs such as oral participation or written contribution as giving us a sense of student feelings of inclusion - as well as to pedagogical norms that view participation as a straightforward vehicle towards more successful learning (Mariskind 2013) - potentially confirming, rather than working to unpack, neoliberal 'tick box' approaches. Further, the draw we felt towards viewing inclusion as participation failed to address questions of alienation, obligation, and hierarchy that such strategies might generate or confirm, rather than work to dismantle.

While teaching methods and activities that encourage participation certainly have their place in fostering inclusion, they should not be considered an exhaustive strategy for achieving inclusive classrooms, nor should they be seen as necessarily dealing equally well with all kinds of difference. In the increasingly individualised neoliberal UK HE context, commitments to complicating 'tickbox' approaches to inclusion remain ever relevant. An intersectional feminist pedagogy should be suspicious of framings of inclusion that aim to see all students meet a predefined framework for participation, or what Burke calls 'a model of inclusion that insists on fitting and/or conforming to the hegemonic and normative frames' $(2017,441)$. In particular, we suggest that the adoption of inclusion at institutional and national levels must not result in localised, context-sensitive practices being displaced by the uncritical application of centrallymandated 'good practice'.

\section{Acknowledgements}


We would like to offer thanks to our colleagues Jacob Breslow and Aiko Holvikiki who supported us and offered their own reflections throughout the module. Special acknowledgement must also go to Sadie Wearing, who both convenes the module and, as Departmental Head of Teaching, is an inspiration in terms of the passion and critical reflection with which she approaches the complex and important task of teaching in Gender Studies. 


\section{References}

Ahmed, S. 2007. “The Language of Diversity." Ethnic and Racial Studies 30(2): 235-256. DOI: $10.1080 / 01419870601143927$

Ahmed, S. 2012. On Being Included: Racism and Diversity in Institutional Life. Durham: Duke University Press.

Ali, S. 2009. "Black Feminist Praxis: Some Reflections on Pedagogies and Politics in Higher Education." Race Ethnicity and Education 12(1): 79-86. DOI:10.1080/13613320802650998

Barnett, P. E. 2011. "Discussions across Difference: Addressing the Affective Dimensions of Teaching Diverse Students about Diversity.” Teaching in Higher Education 16(6): 669-679. DOI:10.1080/13562517.2011.570435

Beaudoin, M.F. 2002. 'Learning or Lurking? Tracking the 'Invisible' Online Student." Internet and Higher Education 5: 147-155. DOI:10.1016/S1096-7516(02)00086-6

Boler, M. 2004. “All Speech is Not Free: The Ethics of Affirmative Action Pedagogy.” In Democratic Dialogue in Education: Troubling Speech, Disturbing Silence, edited by M. Boler, 3-14. New York: Peter Lang.

Brookfield, S.D. and S. Preskill. 1999. Discussion as a Way of Teaching: Tools and Techniques for University Teachers. Buckingham: SRHE and Open University Press.

Brown, W. 2015. Undoing the Demos: Neoliberalism's Stealth Revolution. Brooklyn: Zone Books. 
Burke, P.J. 2015. "Re/imagining Higher Education Pedagogies: Gender, Emotion and Difference." Teaching in Higher Education 20(4): 388-401.

DOI:10.1080/13562517.2015.1020782

Burke, P.J. 2017. "Difference in Higher Education Pedagogies: Gender, Emotion, Shame." Teaching in Higher Education 29(4): 430-444. DOI:10.1080/09540253.2017.1308471

Center for Research on Learning and Teaching. 2015. "Assessing and Addressing our Biases." University of Michigan. Accessed August 23, 2019. http://www.crlt.umich.edu/blog/assessingand-addressing-our-biases

Center for Teaching Innovation. 2019. "Establishing Ground Rules." Cornell University. Accessed August 23, 2019. https://teaching.cornell.edu/teaching-resources/building-inclusiveclassrooms/establishing-ground-rules

Chester, A. and G. Gwynne. 1998. "Online Teaching: Encouraging Collaboration through Anonymity." Journal of Computer Mediated Communication 4(2). DOI:10.1111/j.10836101.1998.tb00096.

Connell-Smith, A. and S. Hubble. 2018. Widening Participation Strategy in Higher Education in England. House of Commons Library. Accessed August 23, 2019. http://researchbriefings.files.parliament.uk/documents/CBP-8204/CBP-8204.pdf

Council of the European Union. 2018. Council Recommendation of 22 Mav on Promoting Common Values, Inclusive Education, and the European Dimension of Teaching. Council of the European Union. Accessed August 23, 2019. https://eur-lex.europa.eu/legalcontent/EN/TXT/PDF/?uri=CELEX:32018H0607(01)\&from=EN

Dreyfus, H.L. 2002. "Anonymity versus Commitment: The Dangers of Education on the Internet." Educational Philosophy and Theory 34(4): 369-378. DOI:10.1111/j.14695812.2002.tb00510.x 
Equality Challenge Unit. 2013. Equality in Higher Education: Statistical Report 2012. Equality Challenge Unit. Accessed August 23, 2019. https://www.ecu.ac.uk/wpcontent/uploads/external/equality-in-he-statistical-report-2013-students.doc

Ellsworth, E. 1989. "Why Doesn't this Feel Empowering? Working through the Repressive Myths of Critical Pedagogy." Harvard Educational Review 59(3): 297-324.

DOI:10.17763/haer.59.3.058342114k266250

Gibson, S. 2015. "When Rights are not enough: What is? Moving towards New Pedagogy for Inclusive Education within UK Universities.” International Journal of Inclusive Education 19(8): 875-886. DOI:10.1080/13603116.2015.1015177

Harlap, Y. 2014. "Preparing University Educators for Hot Moments: Theater for Educational Development about Difference, Power, and Privilege." Teaching in Higher Education 19(3): 217-228. DOI:10.1080/13562517.2013.860098

hooks, b. 1994. Teaching to Transgress: Education as a Practice of Freedom. New York: Routledge.

Karlsson, L. 2015. “Just us, just Discussing: Imagined Homogeneities in the Gender Studies Classroom." Gender and Education 27(6): 654-665. DOI: 10.1080/09540253.2015.1078874

Laurillard, D. 2009. "The Pedagogical Challenges to Collaborative Technologies.” International Journal of Computer-Supported Collaborative Learning 4 (1): 5-20. DOI:10.1007/s11412-0089056-2

LSA Inclusive Teaching Initiative. 2017. "Inventory of Inclusive Teaching Strategies.” University of Michigan. Accessed August 23, 2019. https://sites.1sa.umich.edu/inclusiveteaching/2017/08/24/inventory-of-inclusive-teaching-strategies/ 
Mariskind, C. 2013. “'Always Allowing the Voice': Expectations of Student Participation and the Disciplining of Teachers' Practice.” Teaching in Higher Education 18(6): 596-605. DOI:10.1080/13562517.2013.764861

Matheson, R. and M. Sutcliffe. 2016. "Creating Belonging and Transformation through the Adoption of Flexible Pedagogies in Masters Level International Business Management Students." Teaching in Higher Education 22(1): 15-29. DOI:10.1080/13562517.2016.1221807

Mayuzumi, K., K. Motobayashi, C. Nagayama, and M. Takeuchi. 2007. "Transforming Diversity in Canadian Higher Education: A Dialogue of Japanese Women Graduate Students.” Teaching in Higher Education 12(5-7): 581-592. DOI:10.1080/13562510701595200

Mirza, H.S. and Y. Gunaratnam. 2014. “'The Branch on which I Sit': Reflections on Black British Feminism.” Feminist Review 108: 125-133. DOI:10.1057/fr.2014.13

Miyazoe, T. and T. Anderson. 2011. "Anonymity in Blended Learning: Who Would you Like to Be?" Educational Technology \& Society 14(2): 175-187.

Mohanty, C.T. 2013. "Transnational Feminist Crossings: On Neoliberalism and Radical Critique.” Signs 38(4): 967-991. DOI:10.1086/669576

Parry, S.C. 1996. "Feminist Pedagogy and Techniques for the Changing Classroom." Women's Studies Quarterly 24(3-4): 45-54.

Puwar, N. 2004. Space Invaders: Race, Gender and Bodies Out of Place. Oxford: Berg.

Romney P., B. Tatum and J. Jones. 1992. "Feminist Strategies for Teaching Oppression: The Importance of Process.” Women's Studies Quarterly 20: 95-110.

Rose, D.H. and A. Meyer, eds. 2006. A Practical Reader in Design for Learning. Cambridge: Harvard Education Press. 
Smele, S., R. Siew-Sarju, E. Chou, P. Breton, and N. Bernhardt. 2017. "Doing Feminist Difference Differently: Intersectional Pedagogical Practices in the Context of the Neoliberal Diversity Regime." Teaching in Higher Education 22(6): 690-704.

DOI:10.1080/13562517.2016.1273214

Wazana Tompkins, K. 2016. "We Aren't Here to Learn What We Know We already Know.” LA Review of Books, September 13. http://avidly.lareviewofbooks.org/2016/09/13/we-arent-here-tolearn-what-we-know-we-already-know/

Yannuzzi, T.J. and D. Martin. 2014. "Voice, Identity, and the Organizing of Student Experience: Managing Pedagogical Dilemmas in Critical Classroom Discussions.” Teaching in Higher Education 19(6): 709-720. DOI:10.1080/13562517.2014.901963

Word count: 6949 